\title{
Commentary
}

\section{Primum Non Nocere (First, Not to Harm) and Secundus, Opinio Vulnero (Second, Report the Harm)}

\author{
Scott A. Rivkees \\ Yale Child Health Research Center, Yale University School of Medicine, New Haven, CT 06520, USA \\ Correspondence should be addressed to Scott A. Rivkees, scott.rivkees@yale.edu \\ Received 4 February 2009; Accepted 26 February 2009 \\ Copyright ( 2009 Scott A. Rivkees. This is an open access article distributed under the Creative Commons Attribution License, \\ which permits unrestricted use, distribution, and reproduction in any medium, provided the original work is properly cited.
}

The practice of medicine involves definite and random risks. These risks relate to the unpredictable biology that we deal with; genetic and nongenetic individual variabilities; age and gender; compliance and environmental factors. Uniformly applied, standard approaches to care that have been shaped by clinical trials and modified by empiricism typically result in desired favorable outcomes. In the best of circumstances, though, adverse outcomes occur that need to be collectively harnessed. As new drugs enter our pharmacopoeia, some which are approved based on modest size clinical trials and others being used "off-label," our obligation for vigilance and reporting adverse events (AEs) increases.

Let us consider recombinant IGF-1 therapy. The number of individuals with bonafide growth hormone resistance, the United States Food and Drug Administration (FDA) approved indication [1], is very small [2, 3]. FDA approval of recombinant IGF-1 was based on an experience of about 100 patients [1]. If one looks to situations where other drugs have been recalled from the market place, safety signals were not apparent in preapproval studies involving thousands of individuals [4] (http://www.fda.gov/opacom/7alerts .HTML; http://www.consumerjusticegroup.com/drugrecall/ drugrecalls.html). Only when the drugs hit the market place and use was expanded by thousands more, problems leading to withdrawal of the compounds took place.

Not long ago, a patient of ours had a life-threatening anaphylactic reaction to recombinant IGF-1 and was subsequently shown to have allergy to the preparation by a formal testing [5]. This adverse event was reported to the manufacturer who reported it to the FDA. Last month, I received a call from an endocrinologist in another part of the US describing a possible similar occurrence for this compound, illustrating the need for further collection of clinical experience data for new medications.

Aromatase inhibitors are used "off-label" at many pediatric endocrine centers as a therapeutic for potential height augmentation. Investigational studies of such compounds have revealed modest, but tantalizing increases in longterm growth $[6,7]$. But with the promise comes the poise. Vertebral abnormalities have been found in children treated with one such compound [8]. Although further studies are needed to assess if there are indeed adverse effects of specific aromatase inhibitors or the class of compounds in general on the growing spine [8], it is very likely that many "offlabel" prescribers of aromatase inhibitors are not aware of this potential problem.

Problems also rest with drugs that have been around for so long that they may escape rereview of their safety. Recently, a potential safety concern related to the use of propylthiouracil was brought to the attention of Eunice Kennedy Shriver National Institute of Child Health and Human Development (NICHD), and a special workshop was convened by the Obstetric and Pediatric Pharmacology Branch (OPPB) of NICHD to look at the issue of PTU safety. As detailed in the minutes of the meeting, a serious hepatotoxicity safety concern related to PTU use in children was recognized (http://bpca.nichd.nih.gov/outreach/index.cfm) [9]. Thus, it took 60 years since PTU was introduced before safety concerns related to the use of this compound in children were formally addressed, highlighting the special challenges involved in monitoring drugs that have been in the market for decades.

It is clear that as a discipline, we need to become proactively engaged in drug safety and monitoring issues and assist pharmaceutical companies and regulatory agencies in 
this area. It is a disservice for AEs to be hidden in clinic files. We all need to spare a few minutes and report AEs to the FDA, which is easily accomplished via the MedWatch Program (http://www.medwatch.com/).

In pediatrics in the United States, we have a special opportunity afforded by the Best Pharmaceuticals for Children Act (BPCA) Program to address such issues. The BPCA was signed into law on January 4, 2002, to establish a process for studying on-patent and off-patent drugs used in children. The Obstetric and Pediatric Pharmacology Branch (OPPB) of NICHD leads BPCA efforts on behalf of the $\mathrm{NIH}$ (http://bpca.nichd.nih.gov/index.cfm). As highlighted by the recent workshop on PTU safety, it is hoped that the Lawson Wilkins Pediatric Endocrine Society (LWPES) and the American Academy of Pediatrics (AAP) will partner with OPPB and NICHD and establish new ways to identify drug and therapeutic safety concerns in our field.

In using "on-label" or "off-label" therapies, we need to remember a tenet of medicine "Primum non nocere" (First, not to harm). To this credo, we must add "Secundus, opinio vulnero" (Second, report the harm).

\section{References}

[1] Tercica, Inc., INCRELEX ${ }^{\mathrm{TM}}$ (mecasermin [rDNA origin] injection), Tercica, Brisbane, Calif, USA, August 2005.

[2] Y. Tao, V. Pinzi, J. Bourhis, and E. Deutsch, "Mechanisms of disease: signaling of the insulin-like growth factor 1 receptor pathway-therapeutic perspectives in cancer," Nature Clinical Practice Oncology, vol. 4, no. 10, pp. 591-602, 2007.

[3] A. L. Rosenbloom, "The role of recombinant insulin-like growth factor I in the treatment of the short child," Current Opinion in Pediatrics, vol. 19, no. 4, pp. 458-464, 2007.

[4] B. L. Strom, K. L. Melmon, and O. S. Miettinen, "Postmarketing studies of drug efficacy: why?" The American Journal of Medicine, vol. 78, no. 3, pp. 475-480, 1985.

[5] E. Torjusen, J. Calderon, and S. A. Rivkees, "Anaphylactic reaction to recombinant insulin-like growth factor-I," Journal of Pediatric Endocrinology \& Metabolism, vol. 21, no. 4, pp. 381384, 2008.

[6] N. Mauras, L. G. de Pijem, H. Y. Hsiang, et al., "Anastrozole increases predicted adult height of short adolescent males treated with growth hormone: a randomized, placebocontrolled, multicenter trial for one to three years," The Journal of Clinical Endocrinology \& Metabolism, vol. 93, no. 3, pp. 823831, 2008.

[7] P. Cohen, A. D. Rogol, C. L. Deal, et al., "Consensus statement on the diagnosis and treatment of children with idiopathic short stature: a summary of the Growth Hormone Research Society, the Lawson Wilkins Pediatric Endocrine Society, and the European Society for Paediatric Endocrinology Workshop," The Journal of Clinical Endocrinology \& Metabolism, vol. 93, no. 11, pp. 4210-4217, 2008.

[8] L. Dunkel, "Update on the role of aromatase inhibitors in growth disorders," Hormone Research, vol. 71, supplement 1, pp. 57-63, 2009.

[9] Hepatic Toxicity Following Treatment for Pediatric Graves' Disease Meeting, Eunice Kennedy Shriver National Institute of Child Health and Human Development, Rockville, Md, USA, October 2008, http://bpca.nichd.nih.gov/outreach/index.cfm. 